\title{
El asombro, la afección originaria de la filosofia
}

\author{
Jeannet Ugalde Quintana \\ Universidad Nacional Autónoma de México
}

Resumen: El tema del asombro fue una cuestión muy importante para los primeros filósofos que intentaron dar una explicación del nacimiento de la filosofia y establecer sus fronteras. En el caso de Platón, el asombro es la disposición primera del conocimiento en un doble sentido: antecede al deseo de conocimiento y también lo posibilita. El asombro pone en movimiento las tres partes que integran el alma y gracias a este movimiento llega al descubrimiento de la verdad.

Palabras clave: asombro; filosofia; alma, conocimiento; Platón

\begin{abstract}
The astonishment, the original condition of philosophy". Astonishment was a very important subject for the first philosophers who tried to offer an explanation of the origin of philosophy and to establish its limits. In the case of Plato, astonishment is a disposition of the soul in two senses: it precedes desire of knowledge and also makes it possible. Astonishment moves the three parts of the soul and it is due to this movement that it can reach the discovery of truth.

Keywords: astonishment; philosophy; soul; knowledge; Plato
\end{abstract}


El tema del asombro aparece en los primeros filósofos que intentaron realizar una definición de la filosofia, establecer sus fronteras y brindar una explicación de su nacimiento. Una cuestión importante es que tanto para Platón como para Aristóteles, quienes intentaron por primera vez realizar la tarea ${ }^{1}$ de delimitar la filosofia y ahondar en sus orígenes, la filosofia encuentra su nacimiento en un pathos ( $\pi \alpha \dot{\theta} \theta 0 \varsigma$ ) o estado del alma que lleva a quien lo padece a la búsqueda del conocimiento. Así, para ambos filósofos, el interés por la filosofia proviene de un estado que predispone al conocimiento filosófico y que se caracteriza por cierta pasividad. El asombro es el estado a partir del cual se originaron la filosofia, el mito y el conocimiento en general. Sin embargo, aunque constituye el origen de la investigación de los primeros principios y de todo el saber, el asombro surge en el alma (la cual es considerada como el principio activo en el hombre) de forma involuntaria, siendo un estado que esta experimenta ante la percepción de lo existente.

La importancia de los afectos ${ }^{2}$ en general y la del asombro en específico han sido consideradas por Martin Heidegger en sus lecciones del semestre de invierno de 1937/38 y publicadas en el volumen XLV de la Gesamtausgabe. En ellas se pregunta cómo se encuentra la filosofia vinculada con un temple y considera que esta, a diferencia de todo otro pensar, es el más profundo porque se origina de la pura austeridad y es gracias a esta penuria que emerge de un temple como el asombro. En este mismo sentido, Klaus Held, en su escrito Staunen, Zeit, Idealisierung. Über den griechischen Anfang der Philosophie parte de la distinción que realiza Heidegger entre las formas pre-filosóficas de asombrarse (tales como el "maravillarse", la "admiración" o la "fascinación") y de la diferencia entre estos estados para defender que el asombro filosófico se separa y distingue de los demás porque remueve nuestra significatividad del mundo. Sin embargo, Held considera que si bien Platón permanece próximo al asombro filosófico, se entrega a la búsqueda del saber y se aleja de este estado de ánimo de tal suerte que el asombro deja de ser un estado fundamental de

\footnotetext{
1 Esta explicación la encontramos en el diálogo Teeteto (155d1) de Platón, mientras que en Aristóteles se encuentra en Metafisica, A, 1.

${ }_{2}$ La cuestión de los afectos es tratada por Heidegger en Sein und Zeit, al tematizar sobre la angustia como un estado de apertura.

3 Held, K., Asombro, tiempo, idealización. Sobre el comienzo griego de la filosofia, en: Estudios de Filosofia, 25 (2002), pp. 63-74.
} 
la reflexión filosófica para convertirse en un estado pasajero: "De una parte, Platón permanece aun muy próximo al comienzo de la filosofia en el taumazein. Pero, de otra parte, se entrega al movimiento de la búsqueda curiosa del saber, mencionado al inicio de estas reflexiones, por el cual el pensamiento filosófico se aleja del estado de ánimo del asombro"4.

En este artículo, me interesa mostrar que para Platón las afecciones tienen un lugar importante en el ámbito de la discusión y del conocimiento filosófico. El tema de los afectos en Platón ha sido analizado por Michael Erler en Platon affekte und Wege zur Eudamonie ${ }^{5}$, donde considera que lo que permanece como base de la discusión que realiza Platón en torno a cuestiones tales como la virtud, la valentía, la belleza o la justicia, es la temática afectiva ${ }^{6}$.

En el Teeteto, Platón caracteriza el asombro como un estado del alma que se distingue de otros porque posibilita el conocimiento filosófico de tal manera que puede ser considerado como una apertura al saber. Sin embargo, como afirma Held, el hecho de que Platón, a lo largo de sus diálogos, nos conduzca a aporias y a responder preguntas, no demuestra que para el filósofo el asombro sea un estado pasajero (como sí lo será para Aristóteles), debido a que las aporias y las preguntas propias del discurrir filosófico sugieren que la reflexión filosófica permanece abierta y, por ende, que el asombro es un estado que el filósofo no abandona. Ahora bien, el asombro es para Platón la disposición primera del conocimiento en un doble sentido: por un lado, antecede al deseo de conocimiento y lo posibilita. En este sentido, es previo a todo interés por la sabiduría. Por otro lado, es primero en tanto es necesario que aparezca en el alma para que pueda surgir en ella la aspiración por el saber, constituyendo

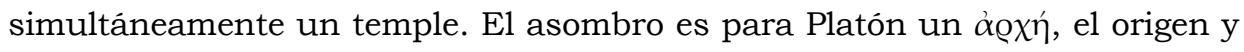
principio de todo el saber, la disposición primera que conduce a la investigación de los primeros principios.

En A Greek English Lexicon, se consideran dos sentidos del concepto de

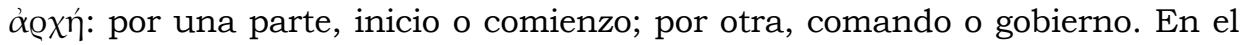

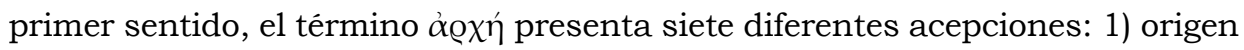
o comienzo de algo, acepción propia de la poesía épica y lírica griega; 2) primer principio o elemento, usada por primera vez por Anaximandro; 3) fin de una línea o cuerda, usado por primera vez por Heródoto; 4) definición matemática

\footnotetext{
4 Ibid., p. 70.

5 Landweer, H. y U. Renz, Klassische Emotionstheorie von Platon bis Wittgenstein, Berlin: Walter de Gruyter, 2008.

6 Ibid., p. 19.
} 
de una curva, usada por Heráclito; 5) lugar donde un río se bifurca; 6) la suma total de algo; y 7) órgano vital del cuerpo. Así, el asombro para Platón en Teeteto

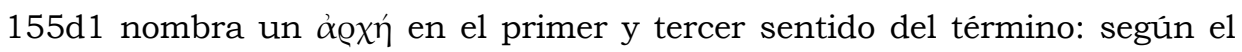
primero, el asombro es principio en el sentido de ser el origen o comienzo del conocimiento y, según el tercero, hace referencia al inicio o comienzo de algo.

En el Filebo, Platón distingue siete estados entre las afecciones del alma que se oponen a la que podriamos considerar la vida propiamente filosófica. Esto se debe a que se encuentran lejanos de la felicidad y se oponen a la investigación de los primeros principios ${ }^{7}$ y las primeras causas. Las afecciones son: la cólera, el miedo, la lamentación, el duelo, el amor, la rivalidad y los celos. Para mostrar de qué manera en Platón las afecciones tienen un papel prioritario para el conocimiento, ya que algunos estados son apertura al saber mientras otras afecciones representan un cierre, analizaré en un primer momento la noción de pathos en el diálogo Teeteto; después, en un segundo momento, presentaré la noción de asombro en este mismo diálogo para realizar, por último, un análisis de la presentación del alma y las afecciones ofrecida por Platón en la República y en el Filebo.

\section{El asombro: un pathos}

En Teeteto 155d3, Platón se refiere al asombro como el estado natural

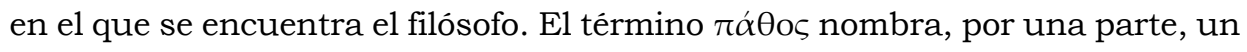
incidente que acontece y para el cual no se determina un agente que lo realiza y, por otra parte, se refiere a un estado del alma que es experimentado de forma involuntaria. El sustantivo " $\pi \alpha ́ \theta 0 \varsigma$ ” se traduce por incidente, accidente, afección o experiencia, proviene del verbo " $\pi \alpha ́ \alpha \chi \omega$ ", que señala el estar afectado o el llegar a un estado, y que se diferencia de una acción porque no tiene su principio motor en quien lo experimenta.

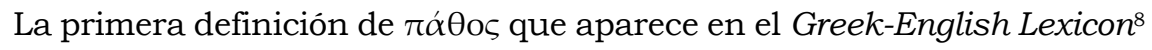
ejemplifica estas dos posibilidades. Por una parte, a partir de Teeteto $193 \mathrm{c}$ se indica que el término páthos nombra algo que ocurre, un acontecimiento que tiene lugar de forma involuntaria. Platón utiliza el término para hablar acerca

7 Thomas A. Szlezák, en su escrito Die idee des Guten als arche in Platons Politeia, considera que si bien Teofrasto y Gaiser piensan que en Platón se encuentra presente una teoría de los principios en plural, para él, en la República, Platón mantiene la idea de la unidad de los principios en la noción del Bien: la virtud tiene una sola forma y esta es la esencia de lo Bueno. Cf. Szlezák, T.A., Die idee des Guten als arche in Platons Politeia, en New images of Plato, Dialogues on the Idea of the Good, Reale, G. y S. Scolnicov (eds.), Academia Verlag, Sankt Agustin, 2002, p. 65.

8 Liddell H.G. y R. Scott, Greek-English Lexicon, Oxford: Clarendon Press, 1996. 
de las impresiones visuales que son observadas gracias a un espejo. A través del espejo, las cosas que transcurren del lado derecho se miran de forma invertida y parece que suceden en el lado opuesto: "ocurre como las impresiones visuales en los espejos que aquellas que están a la derecha transcurren a la izquierda". La percepción de las cosas de forma inversa no acontece porque las cosas tengan ciertas cualidades o propiedades, sino debido a algo externo a ellas como es el espejo. Por ello, con el término páthe se nombra algo que sucede involuntariamente y que no depende de las propiedades de sobre quien acontece el evento.

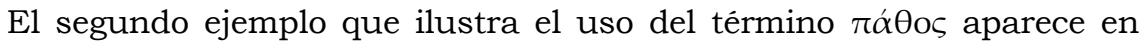
República 612a, donde se encuentra vinculado a la noción de alma ( $\psi \bar{v} \chi \eta ́)$. Con este concepto se nombra los estados que afectan el alma durante la vida de los hombres y se opone fundamentalmente a toda praxis ( $\pi \varrho \tilde{\alpha} \xi ı)$ ).

En el pasaje que va del 611 b al 612a, Sócrates discurre con Glaucón acerca de cómo es posible conocer en verdad el alma y considera que, para conocerla, es necesario analizarla en estado puro, no cuando está arruinada por su relación con el cuerpo y sus vicios. Así, afirma que es necesario mirar el amor que el alma tiene por la sabiduría, observar las compañias que el alma desea y el amor que manifiesta por lo divino. Sin embargo, Sócrates considera que hasta dicho momento en el diálogo, su análisis del alma se ha reducido a un estudio de las afecciones y formas que tiene el alma durante la vida de los hombres: "Cualquiera podría ver entonces qué es y cómo es su verdadera naturaleza, si es compuesta o simple. Por ahora hemos detallado suficientemente, según creo, las afecciones y las formas que adopta durante la vida humana"10. De esta manera, si bien el estado gracias al cual se origina el conocimiento es un estado de pasividad, pues la filosofia y todo el saber encuentran su origen a partir de que el alma se ve afectada por el asombro, el amor a la sabiduría parece ser un estado activo del alma.

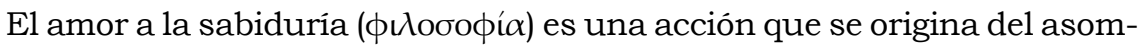
bro. Solo en la medida en que el filósofo padece este estado $(\theta \alpha v \mu \alpha ́ \zeta \zeta)$ puede ir de ese estado pasivo al estado de actividad que implica el amor. De esta manera,

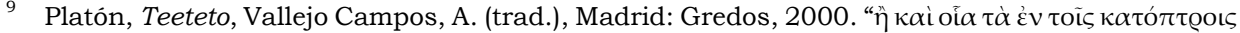

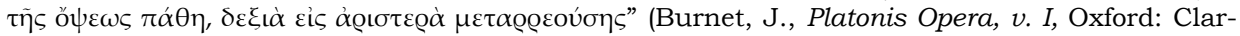
endon Press, 1900 (reimpresión: 1967), 193c).

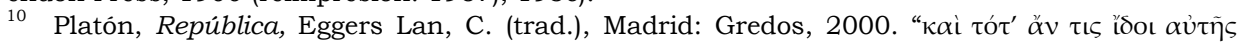

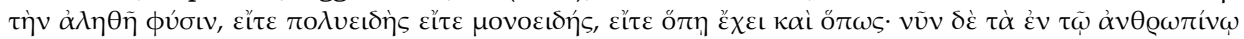

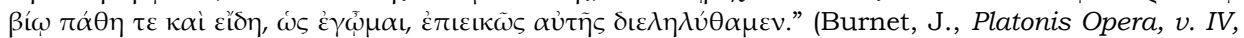
Oxford: Clarendon Press, 1902 (reimpresión: 1967), 612a2-612a5).
} 
el asombro es una afección del alma involuntaria y es en este estado, opuesto a toda acción o praxis, donde encuentra su origen la filosofia.

Para Platón, el estado que dispone al conocimiento filosófico es un estado

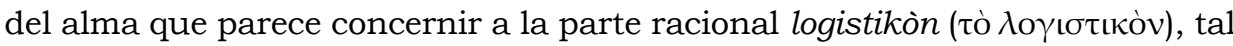
como es presentada en la República. Si bien esta afección es el origen de la filosofia, no es exclusiva de ella, ya que el conocimiento filosófico comparte un mismo origen con el mito. Ahora bien, para Platón, el asombro es una afección a partir de la cual el ser humano toma una mirada en torno a lo existente; posibilita observar todas las cosas a partir de la unidad de su origen y también permite separarse de lo que ha sido observado como una totalidad para formular la pregunta por el principio de todo lo existente. El pasmo primigenio, que origina la filosofia y todo el saber, no acontece ante un objeto particular sino frente a la totalidad de lo que hay.

Aristóteles, en el segundo capítulo del primer libro de la Metafisica, habla del asombro como un estado previo al filosofar, que se origina a partir de la percepción de algún objeto o evento. Ahora bien, el asombro inicial que conduce a la investigación y a la adquisición del conocimiento, conduce a lo contrario $^{11}$ : a asombrarse de que las cosas no sean como son. Sin embargo, el asombro primero, origen de todo el conocimiento, y el asombro segundo, que va en sentido inverso, no pueden ser considerados desde una misma perspectiva. Ellos se distinguen en una cuestión fundamental: en aquello a lo que conducen. El primer asombro, aunque encuentra su origen en la percepción de lo particular, trasciende este ámbito y reconduce la mirada a lo universal, a la investigación de los primeros principios, ya que en la percepción se hace presente lo universal. El segundo asombro surge también ante lo particular, pero en este caso lo concreto se presenta con una gran fuerza y como siendo único, ya que representa una excepción a la norma. Una vez que se han conocido los principios y causas de lo existente, causa extrañeza que las cosas no sucedan como deben suceder. Así, lo particular desconcierta pues no se comporta como debería. Este segundo asombro conduce a la búsqueda de una explicación que explique el cambio o a la verificación de lo que se creía conocido.

\section{La filosofia y el asombro}

Ahora bien, el primero en considerar una relación entre la filosofia y el asombro fue Platón quien, en Teeteto $155 \mathrm{~d} 1$, parte de la experiencia del filósofo

${ }^{11}$ Aristóteles, Metafisica, 983a 11-20. 
para afirmar que lo más característico de él es padecer asombro. De esta manera, el asombro es observado por Platón como una afección que es condición natural de aquel que dedica su vida a la búsqueda de la sabiduría. En un segundo momento, sostiene que el asombro es el origen de la filosofia. La filosofia no tiene otro origen que un sentimiento o estado radical que padece particularmente aquel que ama el saber. Para ilustrar la manera en que la filosofia se genera del asombro, Platón recurre a un mito acerca de la genealogía de los dioses. El mito en este caso funciona como una alegoría, como un elemento que permite aclarar e ilustrar la fuente de generación de la filosofia y su tarea: "Querido amigo, parece que Teodoro no se ha equivocado al juzgar tu condición natural, pues experimentar eso que llamamos la admiración es muy característico del filósofo. Este y no otro es el origen de la filosofia. El que dijo que Iris era hija de Taumante parece que no trazó erróneamente su genealogía"12.

Para explicar de qué manera la filosofia se genera del asombro, Platón va a establecer dos relaciones etimológicas. El primer vínculo etimológico se

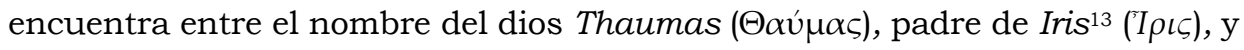
la noción de asombro $(\theta \alpha v \mu \alpha ́ \zeta \varepsilon \iota v)$, origen de la filosofia. Iris encuentra su origen en la divinidad Thaumas. Por su parte, la filosofia proviene del asombro. El dios Thaumas pertenece, en la Teogonía de Hesiodo, a la segunda generación de dioses. Es hijo de Ponto y Gea ${ }^{14}$ y es una divinidad marina que desposa a Electra, con quien engendra a Iris y a las Harpias. Así, bajo esta alegoria, Platón pretende explicar el estado fundamental en el que la filosofia encuentra su origen. La divinidad Iris proviene de Thaumas y, en cuanto, divinidad está vinculado con el asombro, de tal manera que Iris sería la hija de lo asombroso o de lo que inspira asombro. De esta manera, si tanto la filosofia como Iris se originan del asombro y el asombro está vinculado con la divinidad Thaumas,

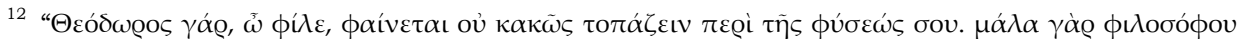

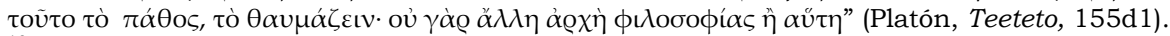

${ }^{13}$ En la Iliada, Iris aparece como la mensajera de los dioses: en el Canto II 786-808 anuncia a Helena el combate de Paris y Menelao; en el Canto III, lleva a Afrodita herida; en el Canto V, transmite a Hera y Atenea las ordenes de Zeus; en el Canto VIII, lleva a Héctor un mensaje de Zeus; en el Canto XI, por órdenes de Zeus, invita a Poseidon a dejar el combate; en el Canto XV, por órdenes de Hera, invita a Aquiles a aparecer en una fosa; en el Canto XVIII, invita a los vientos a soplar sobre la hoguera de Patroclo; en el Canto XXIII, va en busca de Tetis; en el Canto XXIV, transmite la orden a Priamo de rescatar a Héctor. En la Teogonia, como en la Iliada, Iris es la mensajera de los dioses: en 266, se explica su nacimiento: ella es hija de Eléctra y Thaumante; en 780 es considerada como la de los pies ligeros que aparece a espaldas del mar para transmitir un mensaje y, en 784 , se representa con un jarrón de oro para proveer la lluvia y hacer dormir a los que perjuran. $C f$. Homero, Iliada, Bonifaz, R. (trad.), México: UNAM, 2005.

${ }^{14}$ Hesiodo, Teogonía, Vianello de Córdova, P. (trad.), México: UNAM, 2007, pp. 233-239.
} 
a ambas corresponde originarse del asombro y, por la relación de Thaumas con el asombro, el ser divinas porque ambas provienen de lo divino.

La segunda conexión es expresada a partir de las relaciones etimológicas entre el nombre de Iris y el verbo eírein (č̨̣́เv), verbo que Platón en el Crátilo considera como sinónimo de légein ( $\lambda \varepsilon \dot{\gamma} \varepsilon \iota v)$. Iris, tanto en la Iliada como en la Teogonía, es considerada como mensajera de los dioses, la de pies ligeros cuya tarea consiste en trasmitir el mensaje divino a los hombres. En Crátilo 407e408 b, Platón afirma que el nombre de Hermes, la divinidad a la que corresponde ser el intérprete y mensajero de los dioses ante los hombres, tiene algo que ver con la palabra pues es necesario que, en tanto mensajero, toda su actividad se encuentra en relación con el lenguaje ya que a él concierne la interpretación y trasmisión de los anuncios divinos: "En realidad, parece que Hermês tiene algo que ver con la palabra al menos en esto, en que al ser 'interprete' (hermenea) y mensajero, así como ladrón, mentiroso, mercader, toda actividad gira en torno a la fuerza de la palabra"15. En este mismo sentido, Iris, al ser la mensajera, guarda alguna conexión con la palabra. Este vínculo se muestra en el Crátilo a partir del personaje de Sócrates, quien establece una relación entre el nombre de Iris y uno de los verbos del decir. Además, el verbo légein expresa, por una parte, un aspecto distributivo y, por otra, un carácter racional de orden: de la raíz leg-se deriva la noción de $\operatorname{lógos}^{16}$. De esta manera, el nombre de Iris está en relación con la palabra porque su nombre nos explica su tarea. Iris, como Hermes, es la mensajera de los dioses y ambos se sirven de la palabra: "por cierto, que Iris también parece tener su nombre por el hecho de eirein, pues era mensajera"17.

Así, el asombro es para Platón una figura divina pero también la representación de un estado que predispone a la búsqueda del conocimiento. La filosofia,

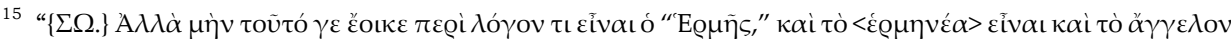

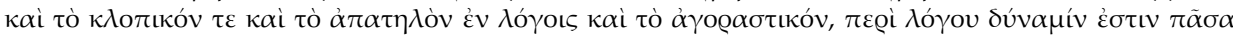

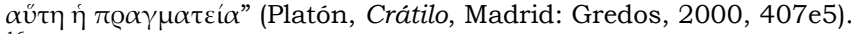

${ }^{16}$ H. Fournier, en Les verbes "dire" en grec ancien, explica que la noción de lógos tiene seis sentidos distintos en su origen en la épica griega, los cuales están vinculados con sus origenes en el término légein. Así, el término lógos presenta : a) un sentido distributivo que es posible observar en la épica griega y que proviene de su raíz leg-, en este caso se traduce como reunión, recolecta; b) un sentido racional cuya traducción es: cálculo, estima, razón, razonamiento; c) un sentido racional enunciativo, que se traduce como discurso, exposición, narración; d) un sentido enunciativo distributivo cuya traducción es: deliberación; un sentido banal puntual que se traduce como alusión, mención, nombre, orden; e)un sentido no declarativo, traducido como actividad, manera; y, por último f) un sentido de inexpresividad. Cf. H. Fournier, Les verbes "dire" en grec ancien, París: Klincksieck, 1946, p. 221.

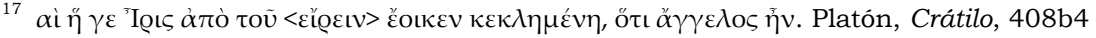


semejante a la divinidad Iris, tiene como fuente de generación al asombro. A ambas concierne el tener un papel intermedio entre los hombres y los dioses. A la filosofia corresponde el estudio del conocimiento de lo más divino, por su parte Iris tiene la tarea de transmitir los mensajes de los dioses a los hombres.

\section{El alma, sus afecciones y el asombro}

En el Filebo, Platón reflexiona si existen estados o disposiciones del alma capaces de proporcionar una vida feliz a todos los hombres y enumera siete afecciones que son dolorosas para el alma. Estas son la cólera, el miedo, la lamentación, el duelo, el amor, la rivalidad y los celos: "Ira, miedo, añoranza y duelo, amor, celos y envidia, y todo lo semejante, ¿no los tienes como pesares del alma sola?"18. Por otra parte, en República 486b10, Platón afirma que el alma del filósofo se distingue de la del resto de los hombres porque es justa y se encuentra dotada de mesura, memoria y facilidad para aprender, de tal suerte que el amigo de la sabiduría es también amigo de la verdad, la justicia, la valentía y la moderación: “¿Has de censurar entonces a una ocupación que no se puede practicar como es debido si no se está por naturaleza dotado de memoria, facilidad para aprender, grandeza de espíritu y de gracia, y no se es congénere de la verdad, de la justicia, de la valentía y de la moderación?"19. De esta manera, si bien en el Filebo se reflexiona acerca de lo que es bueno para todos los hombres y puede procurarles felicidad, Platón distingue dos tipos de cosas que pueden ser consideradas como buenas: por una parte, el placer y el gozo; por otra, la prudencia, el intelecto y el recuerdo. Las primeras cualidades son las que aprecian la mayoría de los hombres mientras que las últimas son las características que Platón nombra en la República para distinguir el alma del filósofo del resto de los hombres. Si bien en República 424a4-424b1 Platón considera que la buena crianza y la educación garantizan la formación de buenas naturalezas, al mismo tiempo afirma que las naturalezas que se encuentran asistidas de manera natural por estos bienes gracias a la educación se tornan mejores. De esta manera, parece que para Platón existen almas que de manera natural tienen cualidades que las predisponen a una vida

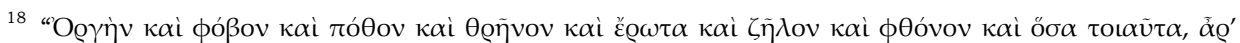

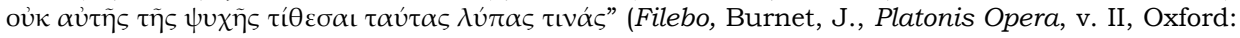
Clarendon Press, 1901, Repr. 1967. 47e).

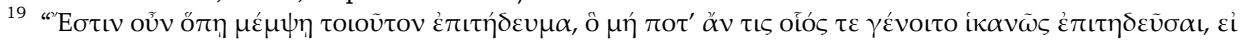

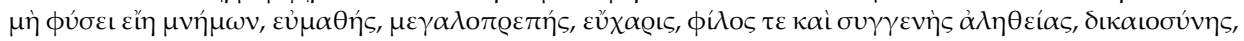

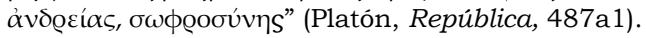


dedicada al conocimiento y la sabiduria, mientras que otras pueden acceder a estos estados a partir de la educación. Ahora bien, en el cuarto libro de la República, Platón indaga acerca de cuál es la constitución del alma, lugar en el que se hacen presentes las afecciones de todos los hombres. El alma, para Platón, tiene una estructura similar a la del Estado, el cual se encuentra compuesto de tres géneros: auxiliares, negociantes y consejeros. En República 441a distingue tres géneros distintos que conforman el alma, a cada uno de ellos concerniéndole una función diferente y cada uno de ellos siendo principio de acción o de pasión en el alma. El alma es una entidad compuesta de una parte racional, una apetitiva y una parte intermedia, auxiliar de la parte racional. Aunque cada una de estas partes representa un principio de acción o pasión en el alma, todas ellas forman una unidad.

La parte racional del alma es la encargada de la reflexión, a ella le con-

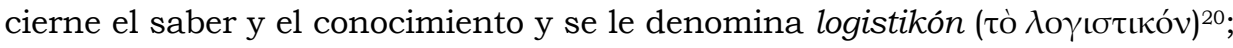
una segunda parte del alma es irracional, es principio de los apetitos, lugar de las necesidades físicas, los deseos corporales, las satisfacciones y placeres,

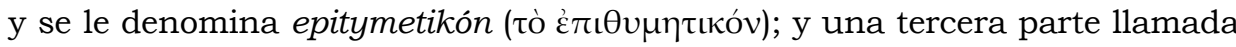

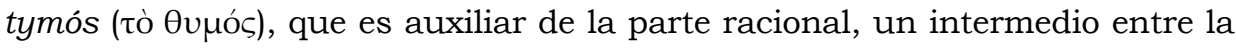
racionalidad y el deseo: "pues no sería infundadamente que las juzgariamos como dos cosas distintas entres sí. Aquella por la cual el alma razona la denominaremos 'raciocinio', mientras aquella por la que el alma ama, tiene hambre y sed y es excitada por todos los demás apetitos es la irracional y apetitiva, amiga de algunas satisfacciones sensuales y de los placeres en general... Tengamos pues por delimitadas estas dos especies que habitan en el alma. En cuanto a la fogosidad, aquello por lo cual nos enardecemos, ¿es una tercera especie, o bien es semejante a alguna de las otras dos?"21. Pese a que en el alma se distinguen

\footnotetext{
${ }^{20}$ Para Oliver Renaut es claro que mientras Platón distingue claramente la función racional,

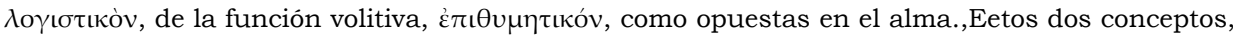
al mismo tiempo, guardan también una relación morfológica: ambos se crean a partir de la forma neutra de un sustantivo o adjetivo con el subfijo tkóv. El subfijo kóv expresa una capacidad, la cual se encuentra vinculada con una actividad. Por otra parte, la tercera función del alma, el $\theta v \mu o ́ s$, no sigue este mismo principio, designa al mismo tiempo una disposición afectiva y un afecto como la cólera, de tal suerte que con esta característica se haga evidente su función intermedia en el alma. $C f$. Oliver, R., Platon la médiation des émotions, París: Vrin, 2014, p.156.

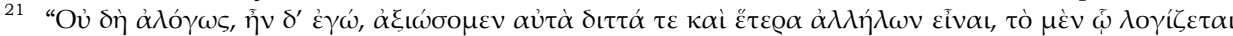

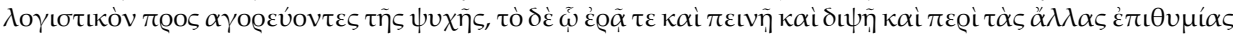

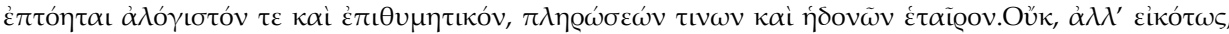

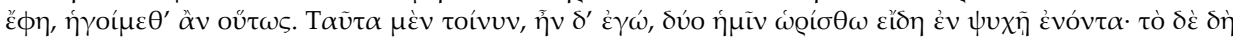

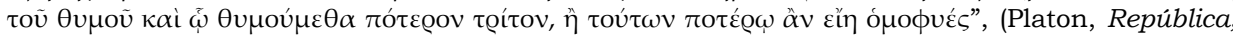
439d4-439e4).
} 


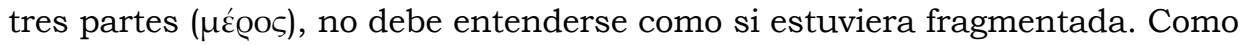
lo subraya Oliver Renaut en Platon: la médiation des émotions ${ }^{22}$, el alma tiene diferentes funciones, cada una de las cuales es el principio de acciones o de pasiones en la vida humana. Así, la analogía que Platón establece entre el alma y el Estado permite mostrar que si bien el alma es una unidad, como lo es el Estado, en ella se pueden observar distintos principios que están vinculados con la tarea que cada uno de ellos realiza y también que el Estado viene a ser una especie de extensión del alma humana.

Para explicar las partes del alma, Platón comienza por oponer la función apetitiva a la racional ${ }^{23}$. De esta manera, cuando se hace presente un deseo ${ }^{24}$ en la parte del alma llamada epitymetikón, como puede ser el de beber agua, al presentarse este deseo el alma del sediento aspira a beber. Este impulso, que se presenta en la función volitiva del alma, conduce a quien tiene este deseo a satisfacerlo. La parte volitiva del alma en la que se genera el deseo no distingue entre aquello que puede satisfacerlo sino que es mero deseo. La parte volitiva solo aspira a la obtención del placer que conlleva a su satisfacción. Ante el impulso ciego, que se genera en la función apetitiva del alma, existe algo que se opone, razona, calcula y determina qué es lo mejor para satisfacerlo, y esta es la parte racional. Platón ilustra la oposición y unidad en la que se encuentran la función volitiva y la racional del alma con la imagen del arquero. Las manos del arquero, para lanzar una flecha, toman el arco realizando dos acciones opuestas: por una parte una mano rechaza el arco y por otra la otra mano lo atrae hacia sí, de tal suerte que en esta oposición de funciones la flecha encuentra un lanzamiento.

En el libro X de República (611c), Platón se cuestiona acerca de la naturaleza del alma y considera que para saber cómo es verdaderamente el alma hay que observarla cuando se encuentra de manera pura, es decir, desligada del cuerpo, y afirma que entonces es posible percatarse si su forma es simple o compuesta por naturaleza: “entonces se verá su verdadera naturaleza, y si es compuesta o simple en su forma, qué es ella y cómo es. Pienso que por el

\footnotetext{
22 “Le vocabulaire des 'parties' de l’âme est moins systématiquement employé que celui des 'espéces' pi des 'genres'. On pourrait alors penser que le terme le plus juste pour désigner les

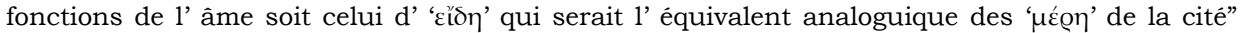
(Renaut, O., Platon la médiation des émotions, Paris: Vrin, 2014.p. 152).

${ }_{23}$ Platón, República, 439a-e.

24 Monique Dixsaut afirma que, aunque Sócrates en el Filebo, al hablar de la estructura apetitiva, pone como ejemplos los más evidentes porque son necesarios, como el hambre, la sed, y el deseo erótico, sin embargo, existen todo tipo de apetitos y lo que el deseo pone en evidencia es que no se desea un objeto determinado sino que el deseo quiere cualquier objeto del mismo tipo.
} 
momento hemos descrito razonablemente sus afecciones y formas durante la vida humana" 25 . De tal manera que el alma en vida se encuentra compuesta de tres partes porque está intimamente vinculada al cuerpo, sus necesidades, deseos, placeres y satisfacciones. Ahora bien, en República 571a7, Platón se interesa por determinar cuántos y cuales son los deseos ( $\tau \tilde{\omega} \nu \dot{\varepsilon} \pi \imath \theta v \mu t \tilde{\omega} v)$ y placeres ( $\tau \tilde{\omega} \nu \dot{\eta} \delta o v \tilde{\omega} v)$ del alma. Para realizar esta tarea, parte de la tripartición del alma y sostiene que hay deseos innecesarios contrarios a toda norma. Estos deseos afloran en momentos en que la parte racional del alma se encuentra dormida y la parte volitiva se niega a dormir e intenta satisfacer sus instintos. La parte volitiva del alma, a la que llama salvaje y bestial, surge con fuerza y pretende dar satisfacción y placer a todos sus deseos: “...cuando duerme la parte racional, dulce y dominante del alma, y la parte bestial y salvaje, llena de alimentos y de vino, rechaza el sueño, salta y trata de abrirse paso y satisfacer sus instintos"26. Por otra parte, hay deseos llamados "mejores" y que pertenecen a la parte racional del alma. Estos surgen cuando hay salud y moderación y cuando se ha logrado, gracias al control de la parte racional del alma sobre la parte apetitiva, adormecer los apetitos y necesidades. Alli no existe en los apetitos un deseo extremo, ni saciedad y hartazgo que atormenten, ya sea por su inquietud o por su complacencia. Quien ha logrado moderar los deseos de la parte volitiva y ha reflexionado sobre sí mismo, examinando las cosas pasadas, presentes y por venir de una manera detenida, puede entonces aspirar a obtener el conocimiento sin ser arrebatado por emociones propias de la parte volitiva del alma: "Pienso, por otra parte, que, cuando uno cuenta con salud y moderación y se echa a dormir tras despertar la parte racional de su alma y banquetearla con bellos discursos y consideraciones, cuando ha llegado a meditar sobre sí mismo sin que los apetitos se hallen en necesidad o en hartazgo para que se adormezcan y no perturben a la parte mejor"27.

Por último, cuando se han puesto en reposo las dos partes del alma, una vez que la parte volitiva ha sido controlada por la parte racional y esta ha

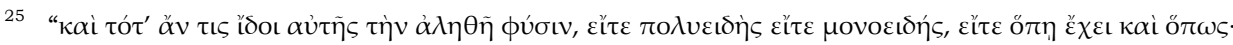

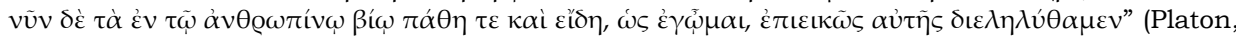
República 612a).

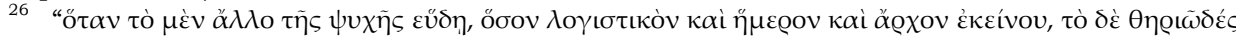

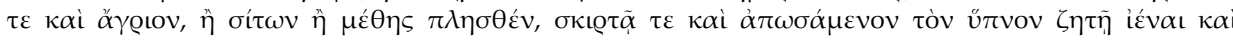

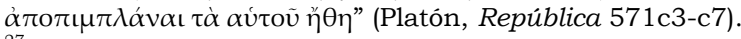

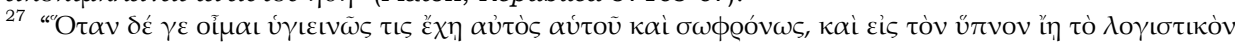

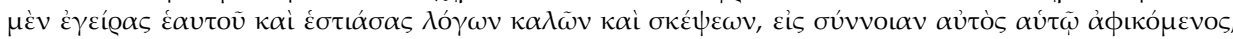

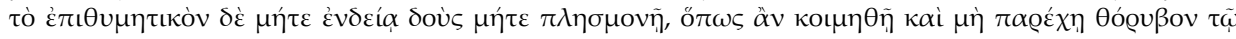
$\beta \varepsilon \lambda \tau i ́ \sigma \tau \omega "$ "(Platón, República, 571d6-572a1).
} 
logrado examinar las cosas accediendo a una pasividad, interviene la tercera parte del alma a la que llama tymos. A la tercera parte del alma corresponde la sabiduría, ella se pone en movimiento para brindar al alma el reposo que implica el descubrimiento de la verdad. A ella le corresponde la sabiduría y por ende la revelación de la verdad ${ }^{28}$. Así, el hombre, dice Platón en República 580d, con una parte del alma se apasiona, con otra aprende y con una tercera, que nombra como particular, el hombre accede a la verdad. Ahora bien, Platón distingue dos tipos de afecciones del alma: unas pertenecen al principio apetitivo de esta y se encuentran ligadas a las necesidades, deseos y placeres del cuerpo, y otras están vinculadas con el principio racional del alma.

Las afecciones del alma concernientes a la función apetitiva representan para Platón un obstáculo para el conocimiento en la medida en que la parte racional tiene que ocuparse de delimitar los deseos y necesidades que se hacen presentes al alma como impulsos en busca de satisfacción. Por su parte, los deseos de la parte racional del alma son aquellos que procuran el conocimiento y la sabiduría. El asombro, en tanto estado del alma a partir del cual se origina un deseo por el saber y el conocimiento, parece ubicarse dentro de las mejores afecciones del alma y pertenece a su función racional. El asombro se genera a partir del deseo de conocimiento y, por lo tanto, del amor a la sabiduria.

En República 586c-d, el filósofo establece una relación entre los deseos de la parte apetitiva del alma y las emociones, de tal suerte que los deseos ${ }^{29}$ que encuentran su origen en la función volitiva están acompañados por emociones que perturban el alma, es decir, que producen placer acompañado de sufrimiento. Así, el deseo de reconocimiento se encuentra acompañado por la envidia, la ambición por la violencia, y el disgusto por la cólera. Por otra parte, los deseos que se encuentran acompañados por la razón persiguen la verdad y alcanzan placeres que no se encuentran mezclados con sufrimiento. A estos placeres Platón los llama placeres más verdaderos. Estos son los que

\footnotetext{
${ }^{28}$ Para Monique Dixsaut, el hecho de que Platón se refiera al alma distinguiendo en ella tres distintas partes no significa que ella sea en sí misma una o múltiple, considera que el alma es ante todo movimiento, y este movimiento puede estar gobernado por alguna de las distintas funciones del alma. La idea de que el alma, una vez que accede a la verdad, alcance la inmovilidad sugiere en Platón la idea de que el alma se mueve para lograr el conocimiento de la verdad. $C f$. Dixsaut, M., Plato, Paris: Vrin, 2003, p. 192.

${ }_{29}$ Mientras en el Filebo 34d-35d Platón se restringe a hablar de los apetitos que pertenecen al cuerpo y son necesarios para su subsistencia, en la República presenta ejemplos de deseos de un género distinto, lo que hace patente es que el origen del deseo se encuentra en el alma misma. Es por ello que para Monique Dixsaut es clafo que la causa del deseo no es ni un estado del cuerpo ni una cualidad del objeto sino el alma es la fuente del impulso. $C f$. Dixsaut, M., o.c., p. 193.
} 
se refieren al saber y al conocimiento. En Filebo 52a1, Platón se refiere a los placeres relativos al conocimiento y observa que de una manera contraria a lo que pasa con los placeres apetitivos, los cuales están mezclados con dolores, los placeres del conocimiento son puros, pues el placer que ellos brindan no implica posteriormente un sufrimiento y dolor. Sin embargo, los placeres puros corresponden a un número limitado de hombres: a los que aman la sabiduría. Así, el asombro es un estado originario de la filosofia porque gracias a él se genera en el alma de los hombres una aspiración por la sabiduría.

$\mathrm{El}$ asombro, en tanto estado del alma, es aquello que pone en movimiento a las tres partes que la integran y es gracias a este movimiento que el alma obtiene la verdad. Así, la verdad puede ser vista como el fin al que aspira el alma en su movimiento. Si bien el asombro es el origen de la sabiduría y del movimiento en el alma que desea obtenerla, el fin es el descubrimiento de la verdad.

Ahora bien, como se mostró en la última parte del escrito, el asombro pertenece a la función del alma llamada "logistikón" y Platón lo expresa en un doble sentido: por una parte distingue los deseos en aquellos que se encuentran ligados a la función volitiva y los que se originan en la función racional del alma y, por otra parte, a partir del mito de Iris sobre el asombro, Platón muestra que este es también origen de la discusión racional. Así, con este mito, Platón muestra que es el asombro el origen de la reflexión y la discusión filosófica, la cual se da no solo gracias a la función racional del alma sino que esta se realiza en el ámbito del logos, el lenguaje propio de la función racional. No obstante, si bien la reflexión filosófica y el conocimiento suceden gracias a la intervención de la función racional del alma, esta necesita previamente y de manera necesaria ser afectada por un estado que la ponga en movimiento, de esta manera el surgimiento de la filosofia queda determinado por el ámbito de las afecciones.

\section{Bibliografia}

Burnett, J., Platonio Opera, Oxford: Clarendon Press, 1900.

180 Dixsaut M., Plato, Paris: Vrin, 2003.

Fournier H., Les verbes "dire" en grec ancien, París: La société de linguistique de Paris, 1946.

Heidegger, M., Ser y tiempo, México: FCE, 1988.

Held, K., "Asombro, tiempo, idealización. Sobre el comienzo griego de la filosofia”, en: Revista Estudios de Filosofia, 25 (2002), pp. 63-74.

Hesíodo, Teogonía, Vianello de Córdova, P., (trad.), México: UNAM, 2007.

Homero, Mliada, Bonifaz Nuño, R. (trad.), México: UNAM, 2005. 
Landweer, H. y U. Renz, Klassische Emotionstheorie von Platon bis Wittgenstein, Berlín: Walter de Gruyter, 2008

Liddell, H.G. y R. Scott, Greek-English Lexicon, Oxford: Clarendon Press, 1996.

Platón, Filebo, Ángeles Durán M. y F. Lisi (trads.), Madrid: Gredos, 1992.

Platón, Crátilo, J. Calonge Ruiz, E. Acosta Méndez, F.J. Oliveri, J.L. Calvo (trads.), Madrid: Gredos, 2000.

Platón, República, Eggers Lan, C. (trad.), Madrid: Gredos, 2000.

Platón, Teeteto, Vallejo Campos, A. (trad.), Madrid: Gredos 2000.

Renaut,O., Platon la médiation des émotions, París: Vrin, 2014.

Szlezák, T., Die idee des Guten als arche in Platons Politeia, en: New images of Plato, Dialogues on the Idea of the Good, Reale G. y S. Scolnicov (eds.), Sankt Agustin: Academia Verlag, 2002.

Recibido: 01/07/2016

Aceptado: 03/02/2017 